\title{
Electrochemical Determination of Maltol in Food Sample Based on Nitrogen-Doped Graphene -Modified Electrode
}

\author{
Huacheng Tang ${ }^{*}$, Zhijiang Li, Ying Wang and Changyuan Wang \\ College of Food science, Heilongjiang Bayi Agricultural University, Daqing 163319, Heilongjiang, \\ $\mathrm{P}, \mathrm{R}$, China \\ *E-mail: huachengtang_163@qq.com
}

doi: $10.20964 / 2017.03 .74$

Received: 23 December 2016 / Accepted: 19 January 2017 / Published: 12 February 2017

\begin{abstract}
There is an easily accessible and low cost approach to generating nitrogen-doped graphene (NG). This method is shown through the combination of high exfoliation speed and covalent metamorphose from the melamine (MA)-graphene oxide (GO) mixture. NGs processed during the temperature of 300,600, and $900^{\circ} \mathrm{C}$ featured X-ray photoelectron spectroscopy (XPS) in a systematic way. As for XPS, graphitic-N, pyridinic-N, as well as pyrrolic-N and are regarded to be three major nitrogen-doped frameworks with different proportions. NG modified GCE exerted a strengthening influence on the electrochemical oxidation process. After optimization, the anodic ultimate current of maltol react was in accordance with its concentration ranging from $0.05 \mu \mathrm{M}$ to $70 \mu \mathrm{M}$, along with the detection limit of $0.02 \mu \mathrm{M}$, has been obtained.
\end{abstract}

Keywords: Graphene; Maltol; N-Doping; Electrochemical oxidation; Annealing temperature

\section{$\underline{\text { FULL TEXT }}$}

(C) 2017 The Authors. Published by ESG (www.electrochemsci.org). This article is an open access article distributed under the terms and conditions of the Creative Commons Attribution license (http://creativecommons.org/licenses/by/4.0/). 